\title{
Incomplete High Radial Nerve Palsy Due to Schwannoma of Radial Nerve in the Upper Arm-A Case Report
}

\author{
Hyun Seong Kang1, Chen Tai Teong1, Jee Eun Park1, Sang Rim Kim¹, Kyu Bum Seo1*, \\ Chang Lim Hyun ${ }^{2}$, Kwang Hun Song ${ }^{3}$ \\ ${ }^{1}$ Department of Orthopedic Surgery, Jeju National University School of Medicine, Jeju, Korea \\ ${ }^{2}$ Department of Pathology, Jeju National University School of Medicine, Jeju, Korea \\ ${ }^{3}$ Department of Orthopedic Surgery, SOO Hospital, Jeonju, Korea \\ Email: *cbnuoskbs@jejunu.ac.kr
}

How to cite this paper: Kang, H.S., Teong, C.T., Park, J.E., Kim, S.R., Seo, K.B., Hyun, C.L. and Song, K.H. (2017) Incomplete High Radial Nerve Palsy Due to Schwannoma of Radial Nerve in the Upper Arm-A Case Report. Open Journal of Orthopedics, 7 , 72-78.

https://doi.org/10.4236/ojo.2017.72009

Received: December 9, 2016

Accepted: February 12, 2017

Published: February 15, 2017

Copyright $\odot 2017$ by authors and Scientific Research Publishing Inc. This work is licensed under the Creative Commons Attribution International License (CC BY 4.0).

http://creativecommons.org/licenses/by/4.0/

\begin{abstract}
A schwannoma is a benign soft tissue tumor composed of Schwann cells. Clinically, the tumor is slow-growing and usually asymptomatic, rarely developing neurological symptoms. We present a case of a 44-year-old female who was diagnosed with an incomplete high radial nerve palsy, showing a wrist drop and extension of fingers due to schwannoma on the radial nerve of the upper arm. The patient showed excellent result after excision of the schwannoma and neurorrhaphy of the radial nerve.
\end{abstract}

\section{Keywords}

Radial Nerve, Schwannoma, Wrist Drop, Incomplete High Radial Nerve Palsy

\section{Introduction}

A schwannoma is considered the most common benign tumor of peripheral nerves composed of Schwann cells and 5\% of these tumors occur in the upper limbs [1]. The tumor is often associated with tingling sensation, which may not be a constant finding at clinical examination. Generally, the tumor grows slowly with minimal symptoms and serious neurological symptom is quite rare. We should check the typical signs of schwannomas, such as positive Tinel's sign and paresthesia. It is possible to identify the tumor's origin through evaluation of imaging studies using magnetic resonance imaging (MRI) and ultrasonography.

A case of schwannoma of the median nerve at the carpal tunnel and the posterior interosseous nerve at the elbow joint causing muscle strength abnormality and sensory loss was reported in a previous study [2] [3]. However, there was no 
reported case of a schwannoma associated with neurological manifestations of the radial nerve of upper arm.

We present a case of a 44-year-old female who was diagnosed with an incomplete high radial nerve palsy, showing a wrist drop and extension of fingers due to schwannoma of the radial nerve of upper arm with excellent result following the excision of the schwannoma and an end-to-end anastomosis of the radial nerve.

\section{Case Report}

A 44-year-old female visited our clinic with extension limitation of the wrist (Figure 1) due to weakness of left wrist since about 7 months ago. She complained of weakness and insensitivity in the first dorsal web space of her left hand. The results of electromyography and nerve conduction velocity test conducted at another clinic prior to her visit at our hospital showed an abnormal finding of the left radial nerve and her symptoms were unresponsive to medical treatment. Under physical examination, extension of the left wrist was impossible (wrist drop). Extension of the thumb and other fingers were possible, but with diminished motor grade (motor grade IV) compared to the contralateral fingers (Figure 2). Patient reported only $20 \%$ of sensory in the dorsal aspect of left thumb, index finger and the first web space compared to the contralateral side. There was no palpable mass and Tinel's sign of the radial nerve was negative at physical examination. The patient was diagnosed with radial neuropathy above the left elbow joint according to the results of electromyography and nerve conduction velocity test at our hospital and an ultrasonography was continued along the anatomical course of the radial nerve.

Ultrasonography showed a thicker radial nerve at the upper arm and an $8 \mathrm{~mm}$ circular sized hypoechoic lesion just below the radial nerve. The radial nerve appeared to be compressed by this lesion and a compressive radial neuropathy or a nerve related tumor was suspected (Figure 3). An MRI scan confirmed an 8 $\mathrm{mm}$ sized, well localized circular tumor in the left upper arm. The tumor showed low signal intensity in T1 weighted image, mild increase of signal intensity in T2 weighted image, and an enhancement pattern surrounding the mass in enhanced T1 weighted image. The mass seemed to be connected with the radial nerve both proximally and distally. Thus, the mass was diagnosed as a nerve sheath tumor (Figures 4(a)-(d)). Removal of the nerve tumor with neurorrhaphy and the possibility of a nerve graft was explained to the patient and the guardian accordingly. Also, the possibility of the delayed neurological recovery from neurorrhaphy or nerve graft was explained prior to surgical treatment.

According to the operative findings, an approximately $8 \mathrm{~mm}$ sized mass was attached to the radial nerve in the lateral intermuscular septum area of the left upper arm. The frozen sectional biopsy done during the operation reported the mass to be a neurilemmoma. Despite our efforts to excise solely the tumor, the resected specimen included the normal radial nerve from the tumor margin was indistinguishable from the normal radial nerve (Figure 5(a) \& Figure 5(b)). Af- 
ter the tumor resection, proximal and distal end of radial nerve was freed in order to carry out an end-to-end anastomosis for the $1 \mathrm{~cm}$ of deficit that had occurred as a result of the resection.

Histologically, the tumor was composed of elongated cells arranged in short bundles with foci of nuclear palisading structure (Antoni type A) along with

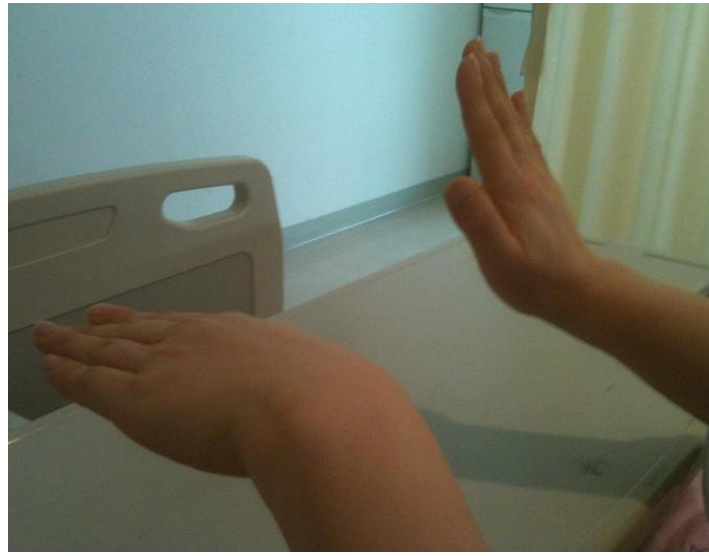

Figure 1. A 44-year-old female presented with impairment of active extension of left wrist while her fingers were active extended.

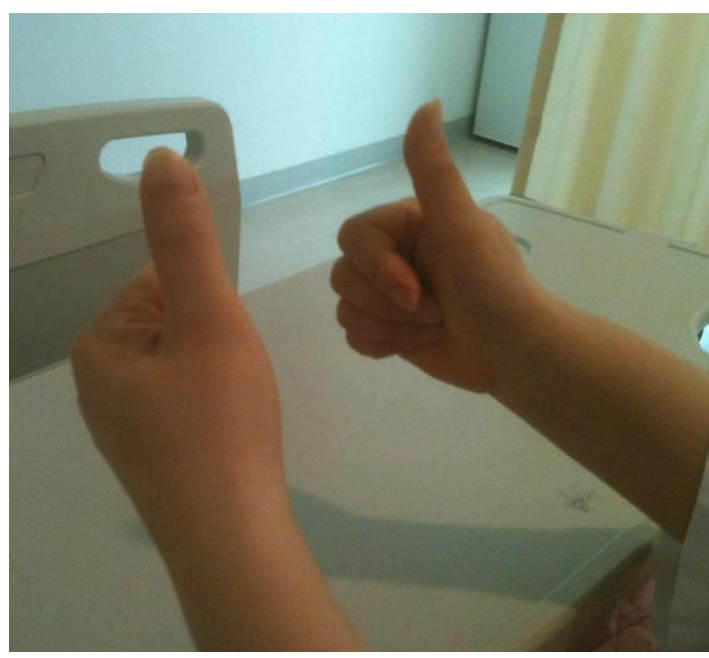

Figure 2. Clinical photograph shows active extension of left thumb.

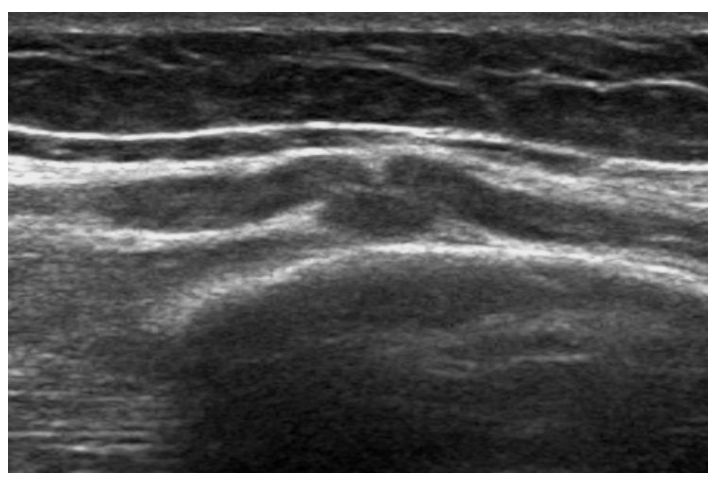

Figure 3. Sonographic image shows hypertrophy and compression of radial nerve with an ovoid hypoechoic mass at left upper arm. 


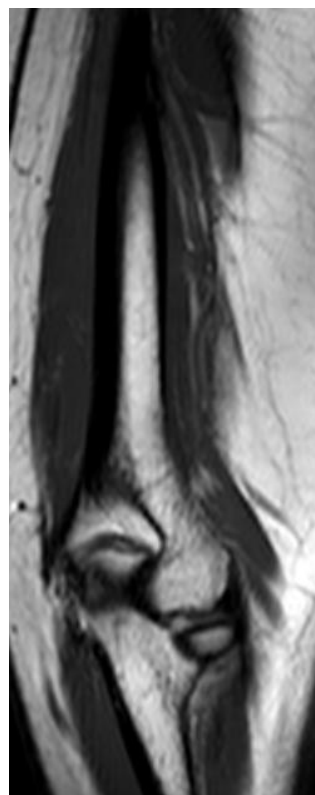

(a)

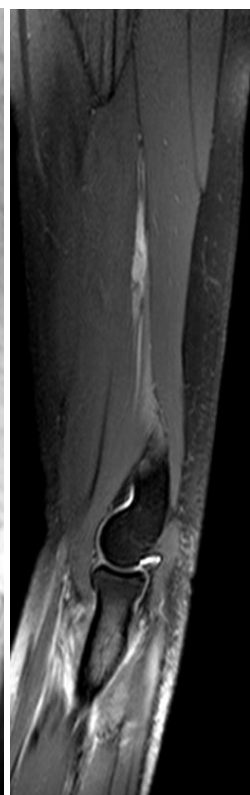

(b)

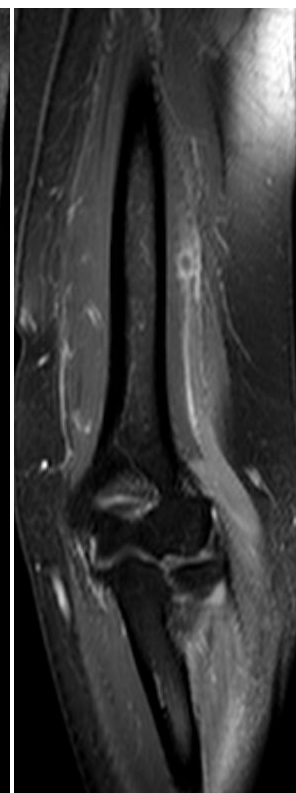

(c)

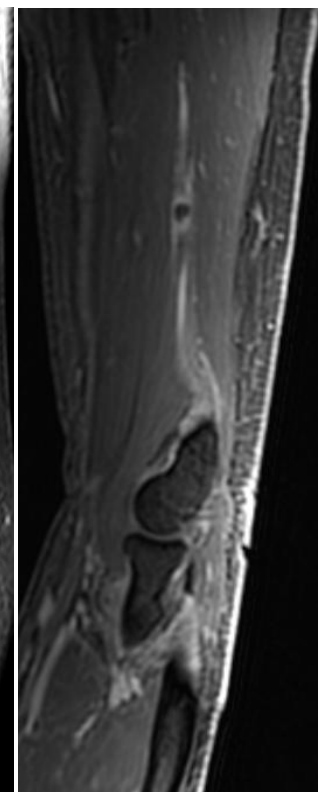

(d)

Figure 4. (a) Coronal T1-weighted magnetic resonance image shows that low signal intensity in the course of radial nerve at left upper arm. (b) Sagittal T2-weighted magnetic resonance image shows that intermediate signal intensity in the course of radial nerve at left upper arm. (c) (d) Coronal and sagittal T1-weighted enhanced magnetic resonance images show well-defined, ovoid mass in the course of radial nerve with peripheral enhancement.

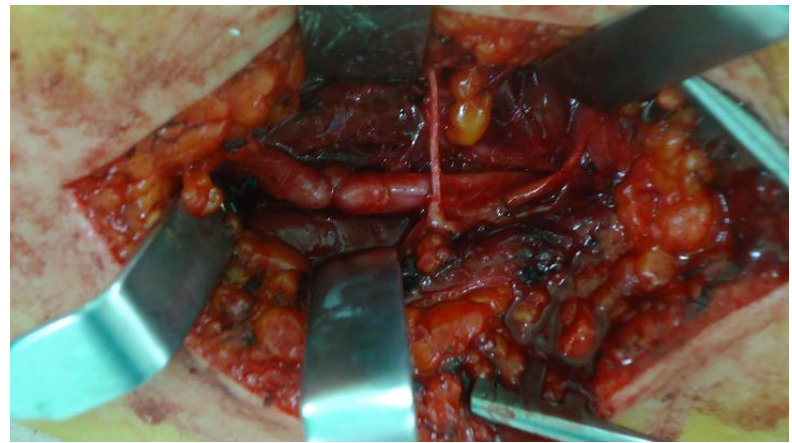

(a)

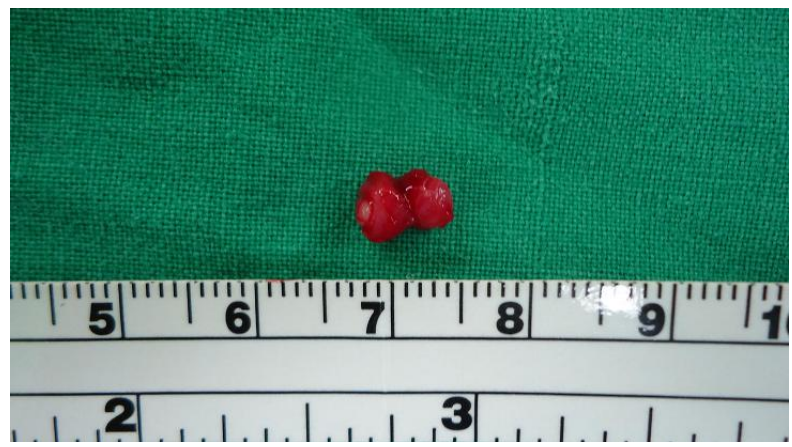

(b)

Figure 5. (a) (b) Intraoperative photograph shows a mass with Hourglass-like constriction in the course of the radial nerve in the lateral intermuscular septum area of left upper arm and an $8 \mathrm{~mm}$ sized mass is completely excised. 
presence of loose areas (Antoni type B). Immunohistochemical stains were performed to identify the origin of Schwann cells revealing the tumor cells nucleus and cytoplasm were positive for S-100 protein (Figure 6).

After the operation, the sensory of the 1 st dorsal web space was diminished by $80 \%$, and the extension of wrist and fingers, including the thumb, were not possible. Two months postoperatively, Tinel's sign at the elbow area was positive and the sensory of the radial nerve distribution. Twelve months postoperatively, there were no clinical signs of recurrence and the motor grade of the radial wrist extensors had recovered to M5, the finger extensors to M4, and the sensory loss was nearly fully recovered.

\section{Discussion}

Schwannomas are the most common type of benign tumor of the peripheral

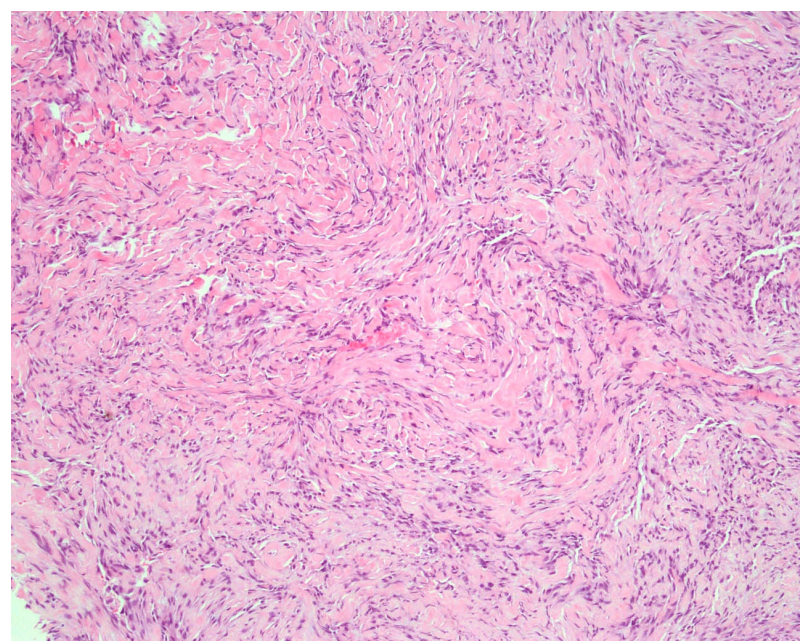

(a)

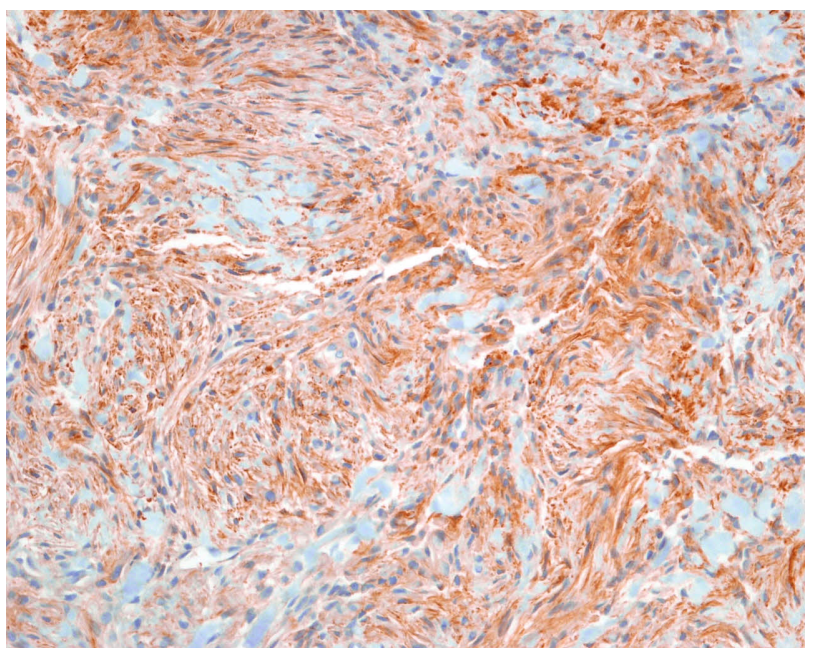

(b)

Figure 6. (a) Microscopically, tumor composed of sheets of tightly parked spindle cells with long oval nuclei and pale eosinophilic cytoplasm (Hematoxylin and Eosin stain, $\times 100$ ). (b) Diffuse strong immunoreactivity with S-100 protein antibody (Immunohistochemical stain, $\times 200)$. 
nerves which usually develop during 20 - 30 years of age [4]. They can occur anywhere in the soft tissue or the viscera, but are most commonly found within major peripheral nerves, especially the sacral nerve in the pelvis or the sciatic nerve. They are commonly located on the flexor surfaces of extremities [5]. Their incidence in the upper limb is higher than the lower limb [6]. Although in most cases, the mass is painless and asymptomatic, if the size of the tumor is large enough, it can cause pain, numbness, paresthesia but rarely muscle weakness [7]. In this case, muscle weakness and sensory abnormalities were present in the area of the radial nerve innervation. As for radial neuropathy, it was difficult for an early diagnosis without a palpable mass or a positive Tinel's sign. In 24 patients treated with schwannoma of the upper extremity, 4 cases had no palpable mass and were assessable only by MRI [4]. The authors primarily performed an ultrasound to locate the exact area of the radial neuropathy and identified the lesion at the upper arm.

At sonographic examination, schwannoma appears as a capsulized mass with a "basket" like internal architecture. However, ultrasonography cannot reliably confirm the attachment of the tumor and the nerve [4]. In this case, we were able to identify the position of the lesion through the ultrasound. However, it was difficult to distinguish between a compression neuropathy and a nerve tumor. An MRI can provide useful information such as the tumor range, anatomic location, size, relationship between peripheral nerve, and preoperative diagnosis including proper planning of the operation.

As for the MRI findings, nerve tumors are known to show intermediate iso-intensity in T1-weighted images, and high signal intensity with clear boundaries and spindles which represent the shades of the soft tissue in T2-weighted images. Often, "Target signs" can be observed in the enhanced images as the surrounding parts show a high signal intensity and the center part shows low signal intensity. The "target sign" may also appear in neurofibromas and this can be helpful in diagnosing a schwannoma. However this cannot be a definitive characteristic finding [4]. In this case, MRI findings show a low signal intensity in $\mathrm{T} 1$ weighted image and a moderate signal intensity in T2 weighted image. Also, the enhanced T1 weighted image showed an enhancement pattern surrounding the tumor and attachment to the radial nerve. Thus, the mass was able to be diagnosed as a nerve sheath tumor.

Surgical resection is the common treatment for schwannoma with satisfactory results, but sometimes surgical resection can be difficult to proceed depending on the pattern of the tumor. In such case, loss of function distal to the lesion can occur as a complication [8]. Especially, resection of a nerve which has an important role on motor and sensory such as the radial nerve, complications such as loss of extension and sensory, distal to lesion may be inevitable. Schwannomas can commonly be treated with only the resection of the nerve, because it is dissected from the surrounding tissues. However, it is difficult to differentiate between normal nerve tissue and the tumor. Therefore, neurorrhaphy or nerve graft is required when neurologic deficiency occur after tumor resection. Ten- 
don transfer can be considered for recovery of the nerve innervated muscle function. In our study, it was difficult to distinguish between the normal radial nerve and the schwannoma, resulting in an approximately $1 \mathrm{~cm}$ deficit. Thus, a neurorrhaphy was performed following the tumor resection.

Once the tumor has been resected, histological examination is necessary for a final diagnosis. Histologically, schwannoma is composed of spindled tumor cells in compact, intense zones (Antoni A) and in hypocellular, myxoid zones (Antoni B). The tumor cells in the Antoni A areas are composed of spindle cells in short bundles with foci of nuclear palisading and Verocay bodies [5]. In the soft tissue tumor, it is reported that the schwannoma stains strong positive in S-100 protein [9]. In our case, schwannoma was confirmed by the positive reaction in S-100 protein through immunohistochemical stains.

\section{Conclusion}

When the mass is not palpable and a positive Tinel's sign is present, it is necessary to identify the lesion by electromyography, nerve conduction velocity, and ultrasonography in the diagnosis of a schwannoma. Preoperative diagnosis should be confirmed by MRI and tumor resection should be performed. Neurologic deficit which may follow the tumor resections, neurorrhaphy or nerve graft could be considered.

\section{References}

[1] Forthman, C.L. and Blazar, P.E. (2004) Nerve Tumors of the Hand and Upper Extremity. Hand Clinics, 20, 233-242. https://doi.org/10.1016/j.hcl.2004.03.003

[2] Aydin, M.D., Kotan, D. and Keles, M. (2007) Acute Median Nerve Palsy Due to Hemorrhaged Schwannoma: Case Report. Journal of Brachial Plexus and Peripheral Nerve Injury, 24, 19.

[3] Werner, C.O. (1991) Radial Nerve Paralysis and Tumor. Clinical Orthopaedics and Related Research, 268, 223-225.

[4] Adani, R., Baccarani, A., Guidi, E. and Tarallo, L. (2008) Schwannomas of the Upper Extremity: Diagnosis and Treatment. La Chirurgia degli Organi di Movimento, 92, 85-88. https://doi.org/10.1007/s12306-008-0049-0

[5] Lee, S.H., Jung, H.G. and Lee, H.K. (1996) Neurilemmoma of Trunk and Extremities. Journal of the Korean Orthopaedic Association, 31, 556-563.

[6] Kehoe, N.J., Reid, R.P. and Semple, J.C. (1995) Solitary Benign Peripheral Nerve Tumours. Review of 32 Years' Experience. Journal of Bone and Joint Surgery. British Volume, 77, 497-500.

[7] Phalen, G.S. (1976) Neurilemmomas of the Forearm and Hand. Clinical Orthopaedics and Related Research, 114, 219-222. https://doi.org/10.1097/00003086-197601000-00024

[8] Shin, D.S., Seo, J.S., Shon, O.J., Han, J.H., Park, S.K. and Byun, S.J. (2006) Sural Nerve Graft after Resection of a Schwannoma in the Sciatic Nerve: A Case Report. Journal of the Korean Orthopaedic Association, 41, 926-932.

[9] Weiss, S.W., Langloss, J.M. and Enzinger, F.M. (1983) Value of S-100 Protein in the Diagnosis of Soft Tissue Tumors with Particular Reference to Benign and Malignant Schwann Cell Tumors. Laboratory Investigation, 49, 299-308. 
Submit or recommend next manuscript to SCIRP and we will provide best service for you:

Accepting pre-submission inquiries through Email, Facebook, LinkedIn, Twitter, etc. A wide selection of journals (inclusive of 9 subjects, more than 200 journals)

Providing 24-hour high-quality service

User-friendly online submission system

Fair and swift peer-review system

Efficient typesetting and proofreading procedure

Display of the result of downloads and visits, as well as the number of cited articles Maximum dissemination of your research work

Submit your manuscript at: http://papersubmission.scirp.org/

Or contact ojo@scirp.org 